\title{
An Empirical Study about Sustainable Growth and Organization Innovation of a Multinational Firm in an Emerging Country
}

\author{
Fumihiko Isada and Yuriko Isada
}

\begin{abstract}
The aim of this research is to clarify the utility of sustainable growth strategies, such as creating shared value, in emerging countries, as well as to discover the organizational capabilities that are effective in order to achieve such a sustainable growth strategy. A survey of the manufacturing firms which have advanced to emerging countries was conducted via questionnaire. In conclusion, the competitive advantage acquired through attempting to solve social problems in an emerging country was a mid- and long-term organizational capability. The organizational capabilities is a skillful utilization of superior human resources well versed in the emerging country's actual condition in the global network which includes a local and a parent nation. It is also the knowledge creation capability through a long-term and relevant strategic alliance relationship between various local partners.
\end{abstract}

Index Terms-Emerging country, multinational firm, organization capability, sustainability.

\section{INTRODUCTION}

The aim of this research is to quantitatively research organizational innovation enabling a multinational firm to grow sustainably in emerging countries. In the conventional international strategy of a multinational firm, manufacturing scale-ups which are expected to lead to low costs, such as low personnel expenses, sales expansion of the low-priced goods in their own country products, etc., were the main purposes of moving into an emerging country. However, such a trans-nationalization strategy includes various problems connected with the economic growth of an emerging country. For example, competitiveness as a production district for a multinational firm declines with an upturn in the personnel expenses of an emerging country, etc., and market competition also intensifies with the rise of companies present in emerging countries. Moreover, various social problems exist and have intensified: for example, as the life cost of an emerging country goes up, economic discrepancy spreads, or environmental pollution expands.

On the other hand, the utility of the strategy in which a private sector business firm tackles with various social problems in emerging countries and grow sustainably with local society is attracting the attention in late years. To solve problems such as economic discrepancy, environmental

Manuscript received November 10, 2013; revised December 26, 2013.

Fumihiko Isada is with the Faculty of Informatics, Kansai University, Takatsuki, Osaka, Japan (e-mail: isada@kansai-u.ac.jp)

Yuriko Isada is with School of Policy Studies, Kwansei Gakuin University, Sanda, Hyogo, Japan (e-mail: yuriko@kwansei.ac.jp). pollution or infrastructure shortages - which were governmental roles conventionally - private enterprises tackle them with innovation as their primary business. Conventional multinational firms rarely treat the BOP (the base of pyramid) market as a target. Conventionally, since the BOP market includes various social problems in addition to low purchasing power, it cannot easily become a target segment. However, its growth potential has attracted attention as so-called 4 billion people's volume zone nowadays. The backgrounds are the progress in an information and communication technologies, etc. For example, Porter et al. have presented the shared value strategy hypothesis, which states that simultaneous implementation of the value of a social problem's solution and the economic value of a company is possible [1]. If a business achieves an innovation that can be used for the solution of a social problem, its competitive advantage will increase. Moreover, Immert et al. indicate the view of reverse innovation, in which product innovation towards the BOP market in an emerging country is connected with global competitiveness as a consequence [2].

A multinational firm's conventional strategy, however, is to aim at promoting in foreign countries the product developed in the parent nation as far as is possible, thus enjoying scale merit; the reverse innovation strategy is contradictory to the conventional strategy. Moreover, in the conventional precedence research, conclusions are not always coherent with regard to CSR activity for companies seeking to solve social problems, and profitability. The result of each study differs, with a positive correlation, a negative correlation or no correlation. It is thought that this nonconformity is caused by differences in the definitions of CSR activities, the diversity of organizational and other factors affecting profitability, and so on.

Therefore, this research focused on the activity of multinational firms against the background of the transitions in the business environment of an emerging country. It aimed at quantitatively verifying the relationship between the above-mentioned sustainable growth strategy and competitive advantage, and the organizational efforts of multinational firms. As a precedent of this research, the following is shown by Isada et al. [3]: although the management strategy followed by a firm in tackling solving social problems as a primary business is not related to the short-term competitiveness of the product itself, it heightens long-term organizational capability. Moreover, as the satisfaction levels of local partner companies or consumers in an emerging country increase, a fiduciary relation with them 
is built, and a forerunner advantage and imitation difficulty increase. This research clarifies necessary organizational strategy towards social problem solution as a succession research of our previous research.

\section{PRECEDENT RESEARCH}

\section{A. Conventional Business Model in Emerging Market}

According to Prahalad et al., multinational firms should move into the layer under the wealthy as their strategic target in an emerging market, but the conventional business model will not work [4]. As multinational firms required growth, they had to compete in the huge emerging markets, but at the time of heightened market entry in the 1980s, multinational firms took an imperialistic view and considered the emerging markets new markets for outdated products. Conventionally, a multinational firm treats an emerging market as complementary to the saturated industrial country market, and has tried to carry from existing product lines to developing countries as they stand. Multinational firms have seldom grasped needs, features, etc. of the local market. Moreover, many multinational firms employ a cheap workforce in factories in developing countries in order to pursue cost efficiencies, and then reimport the products in developed countries. Furthermore, multinational firms have offered only products for the wealthy and burgeoning middle-class markets of emerging countries, and the needs of the base of the business pyramid have been disregarded. Growth in high-volume zones does not work only by readjusting the conventional business model of a multinational firm to an emerging country.

\section{B. Creation of Shared Value}

The creation of shared value (CSV) has been advocated by Porter et al., [1]. A company raises social value by meeting social needs through internalizing external diseconomies, such as environmental pollution, water pollution or traffic congestion. A company raises economic value, such as sales or profit, through CSR as a primary business. CSV is a concept which shares both values: it is a management concept which reconciles social business solutions, business income and improvement in competitiveness, but it also yields a value both to society and the company. The resolution of social issues by a business offering value is added to strategic CSR and integrated into it as CSV. CSV is proposed as a different concept from CSR. Generally CSR tends to be realized in terms of alleviating the adverse effects of an enterprise activity, or as philanthropic activities. Therefore, it seems that business administrators tend to accept CSV by advocating it as a different concept from CSR Although it is difficult to express the effect of CSR in numerical terms, the effect of CSV is expressed numerically as profit to the company.

CSV essentially has three dimensions. First, it is an offering of a product or service which solves a social issue. Second, in it, competitive enhancement of a value chain and a contribution to society coexist. Third, enhancement of the competition base in a corporate development region and the contribution to the region coexist. An example of a business engaged in CSV would be a company working on one of the renewable energies important for the diversification of energy sources or the battle against global warming. Equally, BOP business - which, for example, might develop a customer base of four billion people living on less than $\$ 2$ per day and seek to meet their needs - in many cases operates based on the spirit of CSV. The success of the company's business is also achieved by solving social issues, such as regional economy development, job creation or the eradication of sickness in a developing country. Such business enterprises for BOP markets can also be put into the category of CSV.

\section{Sustainability}

According to Hart, 'sustainability' is a keyword in shareholder value which leads human beings to a sustainable society [5]. The umbrella term 'sustainability' covers many different ways of thinking, issues and concepts and modes of practice. The degree of involvement can be described using a $2 \times 2$ matrix: the first axis is today/tomorrow and the second axis is internal/external an organization. A strategy and a return are considered for each of the four quadrants:

1) Today/internal: pollution prevention (reduction of cost and risk).

2) Today/external: product stewardship, reputation, fairness.

3) Tomorrow/internal: clean technology (innovation, repositioning).

4) Tomorrow/external: the BOP (growth, route).

Pollution prevention involves reducing waste or emissions resulting from the current business activities of the company, and thus reducing cost and risk. Product stewardship is a strategy covering not only the company but all stakeholders in a supply chain. Many multinational firms have confronted problems with fairness in relation to the whole supply chain through consumer strikes, labour disputes in emerging countries, etc. Clean technology is not the continuation of conventional industrial waste suppression technologies. For example, the structural design of products which can easily be disassembled is included in this. The innovation of internal capability which changes the ways of thinking and routines of a company dramatically and results in a repositioning to the use of sustainable technology is necessary. The BOP market is essential in order to take the lead and meet the need for future economic growth. The majority of large-scale corporations which have targeted rich customers in developed countries are insensible to BOP needs and cannot manage this huge market of four billion people. Successful cases are rather exceptional.

\section{The BOP Market}

According to Hart et al., since much of the previous research on international business has targeted the activities of local subsidiaries in developed countries, there is no telling whether the theory can become applied to a developing country (probably only a TOP layer is applicable in the former case) [6]. In order to complement previous research, the new concept of radical trans-activeness (RT) with dynamic capability has been developed. This capability is defined as the capability systematically to authorize, search 
for and integrate the viewpoint of the stakeholder at the fringes in order to respond to the destructive transition in a developing country's market. The stakeholders in developing country markets are divided into core stakeholders and fringe stakeholders. The former comprise investors, customers, government authorities, competitors, employees, non-governmental organizations, suppliers, communities, etc.; the latter stakeholders are the poor, socially vulnerable, isolated, uninterested, non-legitimate, etc. In order for a company to enter a BOP market, both core stakeholders and fringe stakeholders need to be involved and to have full knowledge of confrontations and conflicts. RT is the capability to explore business potential, building a relationship with fringe stakeholders, opening up the framework of knowledge development and experience and considering social constraints and potentialities.

In London et al., the capability necessary for BOP market entry was inductively verified based on 24 cases [7]. Global capability was analysed in terms of three aspects: collaboration with an unorthodox partner, custom-made solution co-creation and construction of local capacity. This capability is almost synonymous with the above-mentioned RT dynamic capability. There is variation in the necessary conditions for these three capability groups between successful and unsuccessful companies in a BOP market, and they influence the growth potential in a lower-layer market. When entering a BOP market, a company cannot depend on the transfer or protection of the knowledge or resources developed in the TOP market. Additional capabilities are needed to surpass those used in TOP markets, such as conventional global operational efficiency, local adaptability and existing knowledge transfer. When entering a BOP market, an effective strategy is for a company to understand the social context and to specify and use its strengths in the business environment concerned. Moreover, a strategy built through a bottom-up process and sharing resources across organizational boundaries is effective. A company with a high capability for social embedding can easily be successful.

\section{E. Stakeholders}

Freeman et al. defined the stakeholders of a company as groups or individuals who can affect the achievements of a company or who are influenced by it. [8]. The success of a company is realized through multiple stakeholders' mutual connection networks. Even if the interests of different stakeholders may be in opposition in the short term, the company has to harmonize them in the long term. In order for a company to pursue profit for those providing funding, it is necessary to create value for other interested parties, and fundamental to the profit-seeking approach is a sense of ethics. A company is successful as long as value is continuously created to the satisfaction of the main stakeholders. By defining the stakeholder concept, the concrete target of a company in terms of implementing social responsibility can be clarified and the goals of social responsibility can be realized.

According to Das et al., a strategic alliance is the spontaneous collaboration between companies aimed at attaining a competitive advantage [9]. Spekman et al., take the view that strategic alliances are close and long-term, and that there is reciprocity between plural partners in terms of sharing resources, knowledge and capabilities with the aim of strengthening each partner's competition status [10]. While networking between companies can be considered important, an alliance is embedded in the management strategy of a company and is expected to play a major role.

Inkpen argued that for an alliance to evolve, ties between the partners which engender trust are important [11]. From Larson's perspective, a business relation based on trust between organizations makes it possible for each to understand their partner's situation and to then achieve high levels of satisfaction and benefits [12]. According to Bradach et al., when partners negotiate with mutual profit and loss and a companion's viewpoint in mind, trust increases further and this relationship is sustained on a long-term basis [13].

In terms of environmental issues, Stafford et al. contend that for a company to derive profit from pioneering the resolution of an environmental problem a green alliance must be realized, taking a long-term outlook and the strategic advantage of a win-win model must be built [14]. According to Mendleson and Polonsky, in engaging with environmental issues, alliance with an environmental NPO is important [15]. When setting the environmental target of a company, in order to understand the environmental added value sought by consumers, alliance with an environmental NPO facilitates understanding of the consumer's viewpoint and potential needs, leading to market opportunities in the future and improvement in the organizational capability of a company. A continuous competitive advantage can be acquired by selecting a suitable environmental NPO. According to Hartman et al., a company can gain profit by initially entering a market with an environmental NPO [16]. When turning an environmental problem into a strategic and attractive business, there must be integration of economic aspects and the social dimension of the resolution of the environmental problem. Through alliance with an environmental NPO, a company can gain public trust, together with the specialized knowledge necessary for the resolution of an environmental problem.

\section{F. Reverse Innovation}

In the field of international business study, the new role of an overseas affiliated firm has been paid attention to in about ten years. Conventionally, the overseas affiliated firm has been considered to be a recipient of the advantage of its parent-nation main office [17], [18]. However, an advantage created in an overseas affiliated firm has attracted attention recently. According to the "meta-national management" view, an overseas-affiliated firm is not dependent on the advantage of a parent nation; knowledge is acquired locally, and an advantage is acquired by spreading it globally [19]. According to the "center of excellence" (COE) view, in a particular activity, an overseas-affiliated firm becomes a central lodgement of a multinational firm [20]. According to "reverse innovation," the innovation which the overseas-affiliated firm yields affects developed countries, and the overseas-affiliated firm bears a more important role [21].

The notion of reverse innovation considers the potential of the BOP market strategy more positively than mere 
penetration at a local level. According to Immelt et al., two kinds of innovation-development in an emerging country and development for developed countries from an emerging country-are contained in reverse innovation [2]. Product development adapted to the customer needs of the emerging country is indispensable, and the product also becomes an innovation which is adapted for the niche markets of developed countries. This means that product proposals which have until now failed to be adopted under a glocalization strategy are developed at the local emerging country level and subsequently offered in developed countries. That is, products that are not taken up under a glocalization strategy are developed through reverse innovation.

Glocalization is a strategy through which an excellent product is developed in the company's own country, is sold on the world market, and is partially changed according to local characteristics. In taking this approach, the trade-off between minimizing costs through globalization and maximizing market share through localization can be optimized. However, the development of the reverse innovation strategy has ended the period in which the glocalization strategy dominated. Like glocalization, though, if multinational firms do not recognize the capability of reverse innovation, it will be difficult for them to survive ten years from now or to ensure good earnings. Succeeding in an emerging country is a necessary condition for remaining prosperous in developed countries.

Nonetheless, although the reverse innovation strategy is indispensable to business, the glocalization strategy is also important for the future. The problem is that they conflict with each other. Centralized product-focused organizational structures and management practices have led to the success of the glocalization strategy. Since the reverse innovation strategy aims at a regional market through a distributed structure, its character is the reverse of the glocalization strategy. It is necessary to overturn two beliefs. The first is that there is a flying geese pattern of development whereby developing country markets develop gradually, similarly to developed countries. In fact, in terms of introducing innovations, it is not unusual for an emerging market to leap ahead of developed countries. The second erroneous belief is that products that correspond to needs peculiar to an emerging country are deficient in terms of their competitiveness in developed countries. On the contrary, such products can create new markets in developed countries by virtue of being low-cost or leading the way in the development of new directions.

According to Govindarajan et al., as the development style of emerging countries is not the same as that in developed countries, models that succeed in developed countries cannot be applied to them [21]. In order to meet the needs of an emerging country, it is important to achieve innovation at a local level from a zero base. In terms of management, for implementing the reverse innovation strategy whereby innovation evolves from an emerging country for global distribution, the authors identify five gaps between developed countries and emerging countries: performance, infrastructure, sustainability, regulatory and preferences.

\section{G. Strategic Alliance and Learning}

According to Rangan et al., the roles of a strategic alliance are ready response to market needs, rapid launch of technology, and learning of a different administrative system [22]. The contemporary characteristics of a strategic alliance are an international strategic alliance, alliance with a rival company, and a business-interface alliance. In such a complicated strategic alliance, the subject of alliance management is promoting learning and maximizing value, sustaining flexibility and defending core competence. According to Hamel et al., the aim of a strategic alliance is the creation of three values [23]: they are co-option, co-specialization and learning. Co-option relates to gaining the majority position in the industry and grasping a defacto standard. Co-specialization is the acquisition of external managerial resources, positioning, skill and knowledge. Learning is studying the skills performed excellently by those in the companion company.

That is, learning mutually is important when seeking to increase presence in a market. According to Badaracco, a strategic alliance is divided into product links and knowledge links [24]. Generally, product links are formed in many cases in order to fill gaps in the product portfolio of a company. A company experiences cost-cutting, diversification of risk, and shortening of lead times through product links. On the other hand, knowledge links are formed when a company accesses the knowledge of the other company and they create new knowledge together. Through knowledge links, new knowledge can be built in the domain of the company. Moreover, knowledge links with many external companies are strengthened mutually, and contribute to the long-term strategy of each company.

According to Inkpen, if a strategic alliance is managed appropriately, it can become a powerful method for creating new organizational knowledge [25]. The feature of this precedence research is that the process of the transference/exploitation of knowledge between an alliance partner and the company was examined. In order to promote knowledge creation effectively through a strategic alliance, the organizational process through which knowledge is transferred from an alliance partner to the company, and the organizational climate which promotes effective practice of knowledge management, are very important. Moreover, Inkpen provides a detailed framework of knowledge acquisition through a strategic alliance [26]. According to this earlier research, the subject of knowledge acquisition is the capability to approach/acquire the knowledge produced in the strategic alliance.

According to Badaracco, in catching the essence of the strategic alliance as knowledge links, knowledge is divided into two types: migratory knowledge and embedded knowledge [26]. Migratory knowledge is provided by a formula, a working drawing, a manual, books, etc., and since it is knowledge which can be expressed clearly, it is knowledge with easy transfer. On the other hand, the transfer of embedded knowledge is slow and it is a knowledge which exists in a complicated social relationship. For example, skill and know-how are the most typical types of embedded knowledge. Such knowledge may be gradually learned slowly through an apprenticeship system, etc. But, once a 
company obtains embedded knowledge, the capability, skill, know-how, and knowledge - which are gained over a longer period of time, as contrasted with migratory knowledge - can be owned.

On the other hand, in promoting strategic alliances in an emerging country, the problem of protection of intellectual property rights is conceived. According to Teece, it has so far been regarded as questionable that the technology which the developed country industry developed spreads to an emerging country industry lawlessly [27]. Then, the pro-patent policy to protect the intellectual property of advanced nations was enforced. According to Teece and Chesbrough et al., since intellectual assets have come to be legally protected through property rights, strategic alliances and open innovation have become possible [27]-[29]. In order for open innovation to be carried out by a strategic alliance which plans industrialization, it is necessary to make the literary property of the company firmly subject to rights. Although it is possible to manage technology with the style of trade secrets in an in-company management model, in order to promote external cooperation, it is necessary for a company to indicate the technology it has to a cooperating company. In order to further research and development globally, it is necessary to extend the rights of intellectual property internationally. It is important also to enhance intellectual property rights and improve the technical market in the emerging country.

\section{H. Meta-National Management and Internationalization at Home}

Yoshiwara has taken up internationalization at home as one factor of the lag in localization [30]. Internationalization at home is an internationalization of the parent company, and is about the condition of foreigner's participation in the process of a decision making in the parent company. Many of presidents, board members, or department managers of the parent company of a Japanese firm were in domestic-operation lines, and the executive who is experienced overseas is still a minority. Moreover, the local workforce of overseas-affiliated firms had barely participated in processes in which important management strategies and plans are drawn up. Japanese also exchanged information between a parent company and an overseas affiliated firm in Japanese in many cases. Such conditions of a parent company had been the barriers to localization of Japanese firms. Even if the local workforce was able to communicate in a foreign language, such as English, it was difficult for the parent company side to respond in many cases. Yoshiwara used a questionnaire with Japanese firms in order to verify the relationship between localization and internationalization at home. As a result, the number of Japanese employees/board members who are experienced overseas, and the number of foreign employees employed in the Japanese head office are positively correlated with localization.

According to Doz et al., it is becoming difficult for a global corporation to build a global competitive advantage based only on technical development ability in a parent nation; production of scientific technology knowledge has decentralized and become global [19]. Against such a background, the viewpoint of "meta-national innovation" has come to attract attention. The general policy conventionally employed in order to increase new products' probability of success was to further heighten internal research and development capability by investing in further research and development and efficient staff. However, the research and development investment efficiency was falling with only internal capability because of the transition of a global competitive environment. The global corporation has been pressed to employ research and development efficient staff from locals regardless of their nationality. As a result, a global corporation needed to possess the knowledge of various cultures as organizational capability.

Activity which approaches and integrates market characteristics from various viewpoints is required so that a new product development project can target a major overseas market. A project leader needs the capability to understand and integrate the various cognitive contexts based on project members' cultural diversity. A project leader is required to have more advanced meta-cognition capability and multicultural management capability, as the mission of a new product development project is to aim at global competitive advantage. As competition is international, radical innovation based on various technical bases is more needed. In order to develop the product of new concepts based on various technologies, technical collaboration capability with various external organizations becomes absolutely necessary.

\section{HYPOTHETICAL DERIVATION}

The aim of this research is to clarify the utility of sustainable growth strategies, such as the shared value strategy, in emerging countries, as well as to discover the organizational capabilities that are effective in order to achieve such a sustainable growth strategy. Some hypotheses which should be verified based on the above-mentioned review of earlier research are derived below.

First, according to the precedent research, such as [2] and [4], the main purpose of a conventional emerging country strategy is sales promotion of low-priced goods in developed countries, and reduction of production costs through cheap personnel expenses, etc. Such a strategy hardly raises the satisfaction level of a local company or consumers, and sustaining growth is difficult. The customized product of the developed country may be accepted in some of wealthy population of an emerging country. As long as the product is superior technically to a local product, certain revenue may be acquired. However, long-term efforts, such as research and development according to real local conditions, are required for a product and service to permeate the "volume zone" market known as BOP. Moreover, if a local economy grows, personnel expenses and other expenses will increase, economic discrepancies will expand, and if a company seeks to sustain lower wages for its workforce it will lead to friction locally. Thus:

1) H1: The product of a multinational firm's high competitiveness will not always improve local satisfaction levels or profitability in an emerging country.

2) H2: The expansion of production by a multinational firm in an emerging country will not always improve local 
satisfaction levels or profitability in an emerging country.

3) H3: The expansion of a sales organization by a multinational firm in an emerging country will not always improve local satisfaction levels or the profitability of an emerging country.

According to the precedent research, such as [1], [5], etc., multinational firms in developed countries are required to offer technology or products which contribute to the solution of social problems, such as industrial infrastructure shortages, environmental problems, or problems of economic discrepancy in emerging countries. In the conventional economy, attempts to solve social problems in developing countries are performed through official development assistance or private enterprise grants. Now, emerging countries are the markets where growth is expected most, and private businesses are investing strategically as their primary business on a long-term basis. When a company tackles the solution of social problems as its primary business, innovation is promoted and the competitive advantage of a company in an emerging country increases.

According to earlier studies such as [14]-[16] etc., in order for a multinational firm to seek to tackle social problems, especially in emerging countries, affiliated construction with various local partners is indispensable. According to [11]-[13], etc., in such a partnership, construction of trust is important. When a multinational firm seeks to solve a social problem, the satisfaction levels of local companies and consumers increases, a fiduciary relationship with various local stakeholders is built, and late coming companies can find it difficult to imitate this. Thus, the first company's emerging country business is expanded sustainably and its revenue increases. It is therefore expected that improvement in the profitability of a company and solution of a social problem will develop sustainably reciprocally.

H4. A multinational firm's effort to solve social problems on emerging countries raises local satisfaction levels, and raises the revenue of the company.

According to earlier research, such as [6], [7], [21], etc., in order to tackle the innovation which targeted "volume zone" especially in the emerging country, a new type of innovation capability is required. The local market, society, and industrial environment in emerging countries differ greatly from those in developed countries, and the development process in the market or industry is not always an analogy of the development process of developed countries. The emerging country is not always following the economic-development process of developed countries simply behind. An emerging country may promptly introduce the newest energy technologies, information and communication technologies, etc., and a different economy or market evolution from those seen in developed countries may be accomplished.

According to [19], decentralization and networking of a research and development location are required in accordance with a diversification of markets including an emerging market. It is expected that the increase of the natives' research and development manager through the merger and acquisition of a local company, a local engineer's employment or cultivation, encourage local innovation.
Therefore, as for a multinational firm, in tackling innovations, such as improvement of industrial infrastructure and solution of environmental problems, it is desirable to transfer managerial resources from the conventional research and development structure based on parent nations, and to promote decentralization and networking of a research location. It is thought that in this way it becomes possible to grasp various societal or economic environments in an emerging country, and to tackle innovation in an emerging country.

H5. If a multinational firm strengthens research and development in an emerging country, it will promote innovation regarding solutions to social problems.

H6. The research and development in an emerging country is strengthened by mergers and acquisitions with local companies, and local researchers' employment or promotion.

Moreover, as mentioned above, in order to tackle innovation regarding the solution of social problems in an emerging country, a strategic alliance with various partners, such as local non-governmental organization, is indispensable. According to earlier research, such as [22], [23], etc., one of the important aims of a strategic alliance is knowledge learning. Moreover, according to earlier studies, such as [11], [24], etc., a transference of the complicated knowledge embedded in the social relation is difficult, and it can be transferred in the prolonged learning by a strategic alliance. According to [19] etc., when implementing meta-national innovation, the management capability of a member aware of various cultures becomes important. In order to achieve innovation through cooperation with the research facility in an emerging country, or various external partners, multicultural management capability in the parent company which integrates a research and development network is necessary. Therefore, in order to raise such multicultural management capability, it becomes important to heighten the diversity of management capability through the acceptance of various efficient staff in a parent nation, etc.

On the other hand, according to [27] etc., in order to promote open innovation, protection of intellectual property rights is necessary. When a multinational firm promotes innovation through an extensive cooperation network including the various partners in an emerging country, environmental management, such as literary property supervision, is also important.

H7. The improvement in multicultural management capability through organizational learning by cooperation with various local partners and the internationalization of a parent company at home strengthens the R\&D capabilities in an emerging country.

H8. Improvement of the research and development environment in an emerging country, such as literary property protection, strengthens the R\&D capabilities in an emerging country.

\section{VERIFICATION OF RESULTS}

\section{A. Verification Approach}

As the verification approach, a survey of employees of the manufacturing firms which have advanced to emerging 
countries among Japanese firms was conducted via questionnaire. The survey was carried out in June 2013, and the author requested the businesspersons who attended my class of a business school, and got responses from 24 which were applicable to the above-mentioned conditions. The questionnaire was measured with the five-point Likert scale system for each question item in order to verify the above-mentioned hypotheses. As an analytic procedure of the questionnaire response, the question items were first integrated with some characteristic components for the principal component factor analysis after eliminating the items which indicated a ceiling effect or a floor effect. A reliability test was performed using Cronbach's alpha coefficient. Then, pass analysis was conducted for the objective variables and principal component scores. The statistics analysis used SPSS ver21 created by International Business Machines.

\section{B. Principal Component Analysis}

Seven principal components were extracted as a result of the principal component analysis with one or more eigen values. Although Cronbach's alpha coefficient was 0.842 for 20 items, and thus was not sufficiently high to confer reliability, in consideration of the significance of each question item, they were adopted as they were.

The first factor relates to industrial infrastructure construction, environmental improvement, distribution network improvement, philanthropy activities, economic discrepancy adjustment, and BOP business, and thus can be named "solution of social problems" factor. The second factor relates to the expansion of research and development activities in an emerging country, facilitating reverse innovation, and thus can be named "local research and development activities" factor. The third factor relates to mergers and acquisitions of local companies, and appointment of local researchers or supervisors, and thus can be named "local research and development capabilities" factor. The fourth factor relates to hiring the natives of emerging countries in a parent company, and partnering a local company or non-profit organization, and thus can be named "organizational learning" factor. The fifth factor relates to expansion of production in an emerging country, and expansion of the exportation to countries other than a parent nation, and thus can be named "production expansion" factor. The sixth factor relates to substantiality of a sales organization and expansion of promotion activities, and thus can be named "sales expansion" factor. The seventh factor relates to the protection activities of intellectual property, and thus can be named "intellectual property" factor.

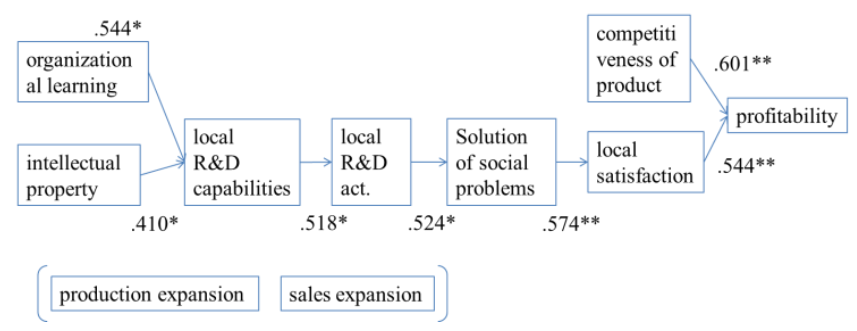

Fig. 1. The result of pass analysis.

\section{Pass Analysis}

The result of statistical analysis is indicated in Fig. 1. ** of the subscript of the correlation coefficient in a figure indicates significance of $1 \%$, and * indicates significance of $5 \%$.

First, the profitability of multinational firms in an emerging country increases with the competitiveness of a product and the local satisfaction level. Solution of social problems has a strong correlation with improvement in local satisfaction levels, although there was no correlation with the competitiveness of a product directly. Moreover, to solve social problems, local research and development was useful and, for that purpose, improvement in local research and development capabilities was useful. Moreover, for improvement in local research and development capability, the organizational learning was useful. Also, consolidating the alliance environmental like an intellectual property protection was important for improvement in local research and development capability. On the other hand, expansion of production in an emerging country, substantiality of a sales organization, etc. did not correlate strongly with firm profitability. As a result of the above analyses, verification results for our hypotheses could be found.

H1 was rejected. The product made with the high technical capabilities of developed countries may achieve a high profitability and customer satisfaction in an emerging country if a customer segment is selected appropriately.

$\mathrm{H} 2$ and $\mathrm{H} 3$ were verified. Even if manufacturing scale-up strategies expect low costs to raise revenue in the short term, it is thought that this is not sustainably effective. For example, in various areas of emerging countries, personnel expenses and other costs increase just as in a developed country, and the various products and services from the emerging country raise local satisfaction levels.

H4 was verified. This becomes the supplementary examination of the research result implemented one year ago by my precedent research. That a social problem solution-oriented strategy raises local satisfaction levels and heightens mid- and long-term competitiveness was also verified in this survey.

H5-H8 were verified. These hypotheses were the main research questions in this survey-based study, added in response to the results of my above-mentioned precedent research. The previous research proved that the competitive advantage acquired through attempting to solve social problems in an emerging country was a mid- and long-term organizational capability. Two kinds of organizational capabilities became clear through this research survey. First, it is a skilful utilization of superior human resources well versed in the emerging country's actual condition, such as a local-society economic affair, in the global network which includes a local and a parent nation. Next is the knowledge creation capability through a long-term and relevant strategic alliance relationship between various local partners.

\section{CONCLUSION}

The aim of this research was to clarify the strategic and organizational capabilities required for the sustainable 
growth of a multinational firm in an emerging country through an empirical study. The following became clear in conclusion. The strategy of a business firm tackling innovation to solve social problem in an emerging country, and aiming at sustainable growth, is thought well of locally, and it is thought that in this way the long-term competitive advantage of a company is attained. Moreover, for that purpose, the long-term innovation of an organization both in a local and a parent nation is required. It is thought that this research finding contributes to the research areas about the growth strategy in the "volume zone" of emerging countries and open innovation as an implication.

The limitations of this research relate to the fact that the questionnaire survey was used only with Japanese firms, and the number of responses was limited to a class in a business school. In future studies, expansion to international comparison, an increased number of surveys and a real local case study are desired.

\section{REFERENCES}

[1] M. E. Porter and M. R. Kramer, "The big idea: Creating shared value. How to reinvent capitalism - and unleash a wave of innovation and growth," Harvard Business Review, vol. 89, no. 1-2, pp. 62-77, 2011.

[2] J. R. Immelt, V. Govindarajan, and C. Trimble, "How GE is disrupting itself," Harvard Business Review, vol. 87, no. 10, pp. 56-65, 2009.

[3] F. Isada and Y. Isada, "A social problem resolution-oriented corporate strategy and competitive advantage: A questionnaire-based study of inter-organizational relations," Journal of International Scientific Publications: Economy and Business, vol. 7, no. 1, pp. 371-393, 2013.

[4] C. K. Prahalad and K. Lieberthal, "The end of corporate imperialism," Harvard Business Review, no. 76, 68-79, 1998.

[5] S. L. Hart, Capitalism at the Crossroads: Aligning Business, Earth, and Humanity, New Jersey: Wharton School Pub, pp.77-78, 2007.

[6] S. L. Hart and S. Sharma, "Engaging fringe stakeholders for competitive imagination," Academy of Management Executive, vol. 18 , no. 1, pp. 7-18, 2004.

[7] T. London and S. L. Hart, "Reinventing strategies for emerging markets: Beyond the transnational model," Journal of International Business Studies, no. 35, pp. 350-370, 2004

[8] R. E. Freeman, A. C. Wicks, and B. Parmar, "Stakeholder theory and the corporate objective revisited," Organization Science, vol. 15, no. 3, pp. 364-369, 2004.

[9] T. K. Das and B. S. Teng, "A resource-based theory of strategic alliances," Journal of Management, vol. 26, no. 1, pp. 31-61, 2000.

[10] R. E. Spekman, T. M. Forbes, L. A. Isabella, and T. C. MacAvoy, "Alliance management: A view from the past and a look to the future," Journal of Management Studies, vol. 35, no. 6, pp. 747-772, 1998.

[11] A. C. Inkpen, "Learning, knowledge acquisition, and strategic alliances," European Management Journal, vol. 16, no. 2, pp. 223-229, 1998.

[12] A. Larson, "Network dyads in entrepreneurial settings: A study of the governance of exchange relationships," Administrative Science Quarterly, no. 37, pp. 76-103, 1992.

[13] J. L. Bradach and R. G. Eccles, "Price, authority, and trust: From ideal types of plural forms," Annual Review of Sociology, no. 15, pp. 97-118, 1989.

[14] E. R. Stafford and C. L. Hartman, "Green alliances: Strategic relations between businesses and environmental groups," Business and Horizons, pp. 50-59, March-April, 1996.
[15] N. Mendleson and M. J. Polonsky, "Using strategic alliances to develop credible green marketing," Journal of Consumer Marketing, vol. 12 , no. 2 , pp. 4-18, 1995.

[16] C. L. Hartman and E. R. Stafford, "Green alliances: Building new business with environmental groups," Long Range Planning, vol. 30, no. 2, pp. 184-196, 1997.

[17] J. H. Dunning, "Explaining changing patterns of international production: In defense of the eclectic theory," Oxford Bulletin of Economics and Statistics, November, pp. 259-269, 1979.

[18] S. H. Hymer, "The efficiency (contradictions) of multinational corporations," The American Economic Review, vol. 60, no. 2, pp. 441-448, 1970.

[19] Y. Doz, J. Santos, and P. Williamson, "Is your innovation process global?" MIT Sloan Management Review, vol. 45, no. 4, pp. 31-37, 2004.

[20] T. S. Frost, J. M. Birkinshaw and P. C. Ensign, "Centers of excellence in multinational corporations," Strategic Management Journal, vol. 23, no. 11, pp. 997-1018, 2002.

[21] V. Govindarajan and C. Trimble, "Reverse innovation: a global growth strategy that could pre-empt disruption at home," Strategy and Leadership, vol. 40, no. 5, pp. 5-11, 2012.

[22] U. S. Rangan and M. Y. Yoshino, "Forging alliances: A guide to top management," The Columbia Journal of World Business, vol. 31, no. 3, pp. 6-13, 1996.

[23] G. Hamel and Y. L. Doz. Alliance Advantage: The Art of Creating Value through Partnering, Boston: Harvard Business School Press, pp. 35-39, 1998.

[24] J. L. Badaracco, "Alliances speed knowledge transfer," Strategy and Leadership, vol. 19, no. 2, pp. 10-16.

[25] A. C. Inkpen, "Creating knowledge through collaboration," California Management Review, vol. 39, no. 1, pp. 123-140, 1996.

[26] A. C. Inkpen, "Learning through joint ventures: A framework of knowledge acquisition," Journal of Management Studies, vol. 37, no. 7, pp. 1019-1044, 2000.

[27] D. J. Teece, "Profiting from technological innovation: Implications for integration, collaboration, licensing and public policy," Research Policy, vol. 15, no. 6, pp. 285-305, 1986.

[28] D. J. Teece, "Reflections on 'Profiting from Innovation'," Research Policy, vol. 35, pp. 1131-1146, 2006.

[29] H. W. Chesbrough and M. M. Appleyard, "Open innovation and strategy," California management review, vol. 50, no. 1, pp. 57-76, 2007.

[30] H. Yoshiwara, "Local president and internationalization at home: The new paradigm of trans-nationalization," The Journal of Business Management, vol. 58, pp. 86-94, 1989.

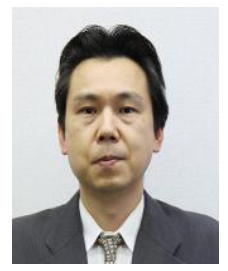

Fumihiko Isada was born in Osaka, Japan. He received Ph.D. degree in economics from Osaka University in 2004. He is a professor with the faculty of Informatics, Kansai University. His research interests are international corporate strategy and innovation management.

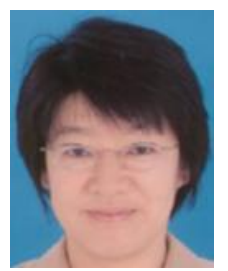

Yuriko Isada was born in Kyoto, Japan. She received $\mathrm{Ph} . \mathrm{D}$. degree in informatics from Kansai University in 2003. She is an associate professor with school of Policy Studies, Kwansei Gakuin University. Her research interests are multi objective optimization, decision support system, and computer simulation. 